\title{
LA RESTAURACIÓN CON SOBREVIVIENTES DEL CONFLICTO ARMADO EN COLOMBIA: UNA PROPUESTA DE ACCIÓN PSICOSOCIAL*
}

\author{
RESTORATION WITH SUVIVORS OF COLOMBIAN ARMED CONFLICT: A \\ PROPOSAL FOR PSYCHOSOCIAL ACTION
}

\author{
VICTORIA LUGO-AgUDELO** \\ Paula Vanessa Sánchez-Agudelo*** \\ CRISTIAN ROJAS-GRANADA****
}

\section{Resumen}

Objetivo. El propósito del presente artículo es presentar los resultados de la indagación bibliográfica sobre la categoría de restauración en relación al acompañamiento psicosocial con los sobrevivientes del conflicto armado colombiano. Metodología. Se revisó la producción a partir del año 2000 en bases de datos especializadas y libros de autores en ciencias sociales que han abordado el concepto. Las categorías que guiaron la búsqueda fueron: definición desde diferentes disciplinas, otros conceptos asociados, aspectos metodológicos y ejemplos. Resultado. Se encontró que la restauración es una acción colectiva y dialógica, que involucra no solo a los sobrevivientes sino también a las comunidades. Conclusión. La restauración es un proceso intencionado que, realizado desde una perspectiva psicosocial, invita a profesionales e instituciones que trabajan con estas poblaciones a abordar los sobrevivientes y las situaciones vividas, no desde lecturas individualistas, sino en su contexto social, histórico, cultural y político.

Palabras clave: restauración psicosocial, sobrevivencia, conflicto armado.

\begin{abstract}
Objective. The purpose of this article is to present the results of the literature review about the restoration category in relation to psychosocial accompaniment of survivors of the Colombian armed conflict. Methodology. Articles published since the year 2000 in specialized databases were reviewed as well as books of social sciences authors who have worked about the concept, were taken into account. The categories that guided the search were: definition of the concept from different disciplines; other associated concepts; and methodological aspects and examples. Results. It was found that restoration is a collective and dialogical action that involves not only the survivors but also the communities. Conclusion. Restoration is an intentional process that, carried out from a psychosocial perspective, invites professionals and institutions who work with those populations to address the survivors and their experiences not just from individualistic views, but in their social, historical, cultural, and political context.
\end{abstract}

Key words: psychosocial restoration, survival, armed conflict.

\footnotetext{
*El presente artículo es resultado de la investigación "Narrativas de sobrevivencia y restauración con víctimas del conflicto armado en Caldas - Colombia”, financiado por la Universidad Católica Luis Amigó (código 49739) y la Universidad de Caldas (código 2041716), en Manizales, Colombia.

${ }^{* * *}$ Universidad de Caldas. Manizales, Colombia. E-mail: victoria.lugo@ucaldas.edu.co -

(1) orcid.org/0000-0002-5096-4105 Google Scholar

**** Universidad Católica Luis Amigó. Manizales, Colombia. E-mail: paula.sanchezag@amigo.edu.co -

(1) orcid.org/0000-0002-6624-7087 Google Scholar

*** Universidad de Caldas. Manizales, Colombia. E-mail: cristian.rojas@ucaldas.edu.co -

(1) orcid.org/0000-0001-9190-2664 Google Scholar
}

rev. eleuthera. 19 , julio-diciembre $2018,55-73$ 
La restauración con sobrevivientes del conflicto armado en Colombia: una propuesta de acción psicosocial

\section{Introducción}

El objetivo del presente artículo es profundizar conceptualmente en la categoría de restauración. La importancia de esta categoría radica en las posibilidades que ofrece para abordar los procesos de recuperación psicosocial con los sobrevivientes del conflicto armado, de una forma más holística y generativa, entendiendo por sobrevivientes tanto a las víctimas como a los victimarios. El proyecto de investigación "Narrativas de sobrevivencia y restauración con víctimas del conflicto armado en Caldas - Colombia”, tuvo como propósito comprender los procesos de sobrevivencia llevados a cabo por las personas afectadas por el conflicto armado en Caldas, para promover el reconocimiento de su capacidad de agencia y, de esta forma, aportar a los procesos de recuperación psicosocial en el marco del post-acuerdo en Colombia. A partir de un marco socioconstruccionista (Gergen, 1994), los investigadores llevaron a cabo encuentros narrativos, dialógicos y artísticos para conocer y reconocer las historias alternativas de sobrevivencia de un grupo de hombres y mujeres que sufrieron desplazamiento forzado en diferentes regiones del país. La revisión de antecedentes se centró en las categorías de sobrevivencia y restauración, de manera que pudiera diferenciarse lo que se entiende por cada una de ellas y a su vez complementarse, con el propósito de aportar a los procesos de recuperación psicosocial para el post-acuerdo.

Para realizar la indagación bibliográfica sobre la categoría de restauración, se tomaron en cuenta autores clave en las ciencias sociales que hayan abordado el concepto o algunos relacionados, y también artículos publicados a partir del año 2000, obtenidos a través de las bases de datos de EBSCO, Redalyc y SciELO. Las categorías que guiaron la búsqueda fueron: definición de restauración desde diferentes disciplinas, otros conceptos asociados, aspectos metodológicos y aplicaciones en problemas concretos. Después de identificados los artículos, se procedió a elaborar fichas analíticas que fueron clasificadas en matrices y posteriormente comparadas entre sí, de acuerdo a las categorías analíticas.

Como el énfasis de este artículo es la restauración, de forma introductoria se presenta lo que se entiende por sobrevivencia y su relación con la restauración. Se reconoce que la recuperación psicosocial de los sobrevivientes al conflicto armado en Colombia (víctimas y victimarios) puede desarrollarse, al menos, de dos maneras: a) por medio de todas las acciones adelantadas por los mismos sobrevivientes, que les ha permitido enfrentar los efectos que el conflicto armado dejó en sus vidas; a esto se denomina sobrevivencia; y b) por los procesos de recuperación en los que participan intencionalmente terceros no afectados directamente por el conflicto armado, y a los que se refiere este artículo como restauración.

La sobrevivencia entonces, se refiere al repertorio de acciones que personas, familias y comunidades desplegaron individual o colectivamente y que les permitió, en primer lugar, salir 
con vida de situaciones extremadamente riesgosas y, en segundo lugar, enfrentar los efectos materiales, simbólicos, imaginarios, relacionales y culturales, que dejó el conflicto armado en sus vidas. Como plantea Das (como se citó en Ortega, 2008), las personas:

\section{(...) padecen, perciben, persisten y resisten las diferentes formas de violencias, recuerdan sus pérdidas y les hacen duelo, pero también las absorben, las sobrellevan y las articulan a su cotidianidad, las usan para su beneficio, las evaden o simplemente coexisten con ellas. (p. 20)}

Si bien los acontecimientos del conflicto armado han causado dolor y sufrimiento, esas violencias también son transformadas por un repertorio de acciones, que los sobrevivientes como actores sociales conjuntamente han llevado adelante como recursos para enfrentar la adversidad, para hacerle frente a los impactos en sus redes simbólicas e imaginarias.

Asumir la categoría de sobrevivencia no significa desconocer el sufrimiento al que personas, familias y comunidades han estado sometidas a razón del conflicto armado en Colombia. Dicho sufrimiento se entiende como social desde la perspectiva de Kleinman, Das y Lock (1997): "El ensamblaje de problemas humanos que tiene sus orígenes y consecuencias en las heridas devastadoras que las fuerzas sociales infligen a la experiencia humana” (p. 25), es decir, es un sufrimiento que incluye múltiples dimensiones de la vida humana, como la salud, la moral, la religión, lo jurídico, entre otras, y su causa es debida a la violencia política y social, que afecta y descompone el tejido comunal.

El concepto de sobrevivencia, mucho menos el de restauración, desconoce la responsabilidad de terceros en la recuperación de los sobrevivientes. Y cuando se hace referencia a terceros se incluye a todos aquellos que no fueron afectados de forma directa, es decir, todos los miembros de la nación y el Estado en su conjunto, quienes desde la perspectiva de la coresponsabilidad por los daños sufridos, tendrían que participar en los procesos de recuperación de los sobrevivientes al conflicto armado.

El concepto de restauración permite integrar diferentes niveles y perspectivas para que la recuperación psicosocial sea generativa y holística. La discusión incluye una revisión del uso del concepto de restauración en diversas áreas del conocimiento. Luego, se aborda la restauración psicosocial, a partir del análisis de las características que se consideran centrales: el reconocimiento de los sobrevivientes y del sufrimiento social vivido, la restauración como acción conjunta y dialógica y la restauración como práctica simbólica situada. 
La restauración con sobrevivientes del conflicto armado en Colombia: una propuesta de acción psicosocial

\section{Discusión}

\section{La restauración desde distintas áreas de conocimiento}

La palabra restauración significa "acción o efecto de restaurar", viene del latín restauratio -ōnis y se compone del prefijo re- (hacia atrás, de nuevo), stare (estar en pie), más el sufijo -ción (acción y efecto $)^{1}$, es decir, "volver a poner en pie". De acuerdo con el Diccionario de la Lengua Española ${ }^{2}$, restaurar significa "reparar, renovar o volver a poner algo en el estado o estimación que antes tenía”; sin embargo, el significado de la palabra varía según el contexto de uso. A continuación se presentará una breve descripción de las principales características del concepto en distintas áreas de conocimiento, para así comprender mejor su complejidad y riqueza y profundizar en la categoría de restauración psicosocial con sobrevivientes del conflicto armado, propósito de este artículo.

En el campo de las neurociencias, se sabe que las funciones del cerebro se pueden ver afectadas por factores congénitos, enfermedades o accidentes; sin embargo, mediante procesos que ayudan a la restauración neuronal y que involucran profesionales de distintas disciplinas (terapeutas físicos, neuropsicólogos, educadores, etc.), se busca que el cerebro pueda alcanzar su funcionamiento óptimo, dentro de los límites propios de cada tipo de afectación neuronal (Vera et al., 2007).

Por otra parte, en el campo de la ecología, cuando hay una afectación al ambiente, por ejemplo, un incendio forestal o la degradación de un arrecife de coral, lo que ocurre seguidamente es un proceso de regeneración natural, espontánea, por parte de los mismos organismos que componen el ecosistema y este proceso puede ser potenciado por medio de la restauración, la cual es inducida por el ser humano (Alanís et al., 2010; Pizarro, Carrillo y García, 2014).

Como se puede ver en estos dos campos, las neuronas y los ecosistemas tienen en común que cuentan con recursos propios para responder de forma natural a los daños sufridos y, cuando es el ser humano el que actúa para favorecer este proceso, entonces se denomina restauración. Haciendo una comparación con el tema de este artículo, los sobrevivientes viven un proceso espontáneo de regeneración (sobrevivencia) al daño causado por el conflicto armado, que llevan a cabo acudiendo a sus propios recursos y los de su comunidad, y los procesos de restauración, al igual que en el cerebro o en un ecosistema, requieren de la participación de terceros (profesionales, instituciones, comunidad, Estado). Todos los seres vivos tienen en común la capacidad de respuesta, lo que no se puede decir de objetos inanimados que dependen totalmente del "restaurador" para su recuperación.

\footnotetext{
${ }^{1}$ Véase: http: / / etimologias.dechile.net/?restauracio.n

${ }^{2}$ Versión en línea del Diccionario de la Lengua Española: http:// dle.rae.es/?id=WEDDoZm
} 
Los procesos de restauración del ambiente suelen ser implementados por profesionales de distintas áreas, sin embargo, es igual de importante la participación de las comunidades que habitan en el territorio, dado que estas pueden ser responsables del deterioro del ambiente o agentes activos en su recuperación (Mazón, Sánchez, Díaz, y Gaviria, 2017). Un ejemplo de este tipo de procesos es una experiencia denominada "restauración ecológica participativa", en la cual se trabajó con jóvenes de Ciudad Bolívar en Bogotá, Colombia, con el fin de contribuir al mejoramiento de las condiciones ambientales de la localidad y, de este modo, mejorar la calidad de vida de sus habitantes (Camacho, 2016). En este sentido, también cabe señalar la relación que se ha establecido entre el ambiente y el bienestar psicológico, a partir de la categoría de "ambientes restauradores" (Gressler y De Araújo, 2013), la cual se refiere a las cualidades del ambiente que pueden favorecer los procesos de promoción o recuperación de la salud mental en una comunidad (Martínez, Montero, Córdova y Vázquez, 2014).

De otra parte, los procesos de restauración aplicados a entidades no biológicas como los objetos producidos por el ser humano, dan cuenta de la historia de una comunidad, pues se asume que dichos objetos se encuentran cargados de un valor cultural importante para su identidad (Molina, 2005). Para algunos autores, la restauración en el campo de los bienes culturales es una lucha de la humanidad contra el tiempo o "el intento de prolongar su ya reducida escala temporal” (Squassina, 2016, p. 25), es decir, la restauración tiene una intencionalidad de mantener la memoria colectiva prolongando la vida útil de un objeto culturalmente valioso (desde el punto de vista simbólico, histórico, religioso o artístico), a partir de intentar detener o contrarrestar el deterioro que sufren los objetos por su uso, por efectos de la naturaleza o por la acción intencionada o involuntaria del ser humano (Recondo, 2006).

Desde el punto de vista de la restauración de bienes culturales, se restaura lo que ha sido dañado y se considera valioso. Este daño no debió haber ocurrido, se tuvo que haber prevenido y no debería repetirse en el futuro. Pero dado que ocurrió, que ha lesionado severamente una existencia valiosa, dicha existencia requiere ser restaurada. El valor radica no solamente en el objeto mismo, sino también en lo que puede aportar a otros, a las generaciones presentes y futuras. Como plantea González (2017):

\footnotetext{
(...) no se trata solamente de una indagación trivial en el pasado, sino que constituye una pieza clave para explicar e interpretar el presente, más aún, contribuye a construir el futuro de las personas a quienes atañe, las ayuda a apoyarse sobre lo vivido para ampliar sus horizontes, comprenderse a sí mismas, su entorno, su posición en el mundo y a orientar sus proyectos y sus acciones. (p. 135)
}

Alcántara (2006) plantea que la restauración permite recuperar la unidad potencial de la obra, entendida como la capacidad de reconstruir una imagen completa a partir de los fragmentos 
disgregados, que conservan cada uno de ellos la huella de la unidad original. Cuando se hace referencia a personas, grupos o comunidades que han sufrido daño, la restauración significa también recuperar el valor de esta existencia respetando su integridad, su dignidad, su originalidad, las transformaciones que ha sufrido a lo largo del tiempo y su potencialidad, para que esta vida se siga convirtiendo en algo más y no quede atrapada en el daño sufrido Lugo (2017).

Toda restauración tiene implicaciones en los planos ético, estético, político y económico, toda vez que está relacionada con la identidad de un colectivo y con la forma en que cada sociedad responde preguntas como: ¿Qué es valioso para ser restaurado y qué no lo es? ¿Por qué? ¿Cuánto se está dispuesto a invertir en esa restauración? ¿A quiénes beneficia mantener viva una memoria a través de la restauración de un determinado patrimonio? ¿Qué relación tiene la historia y los sistemas políticos con la restauración?

Respecto a la dimensión económica de la restauración, cabe resaltar que existen una serie de beneficios secundarios que muchas veces no son visibles de forma inmediata, como el aumento del sentido de pertenencia y de bienestar de una comunidad, que pueden redundar en una mayor productividad económica (Zendri, 2011; Asociación Restauradores Sin Fronteras, 2012). En cuanto a personas que han sido afectadas por el conflicto armado, cobra mayor relevancia la pregunta sobre si es importante y necesario invertir en su restauración, para que, por ejemplo, sean productivas económicamente o si no se considera relevante por no ser personas "necesarias" para el sistema económico (Mbembe, 2011). Si, como plantea Butler (2010), es una vida que se considera valiosa, digna de ser vivida y llorada, entonces sería necesario invertir en su restauración. La pregunta referida a si este daño debería restaurarse y por qué, tiene implicaciones éticas, políticas y económicas que involucran a todos los miembros de la sociedad.

A continuación se discutirá la noción de restauración aplicada a sistemas sociales y políticos, desde los campos de la sociología, la ciencia política y las ciencias jurídicas. Varios países del mundo tuvieron gobiernos dictatoriales durante el siglo XX; el regreso de estas sociedades a gobiernos democráticos se entiende como "restauración democrática" o "restauración republicana" (Anchorena, 2016), lo cual implica un proceso complejo de lucha de grupos minoritarios o grupos políticos contradictores por lograr la transición a un sistema de reconocimiento de las diferencias y de participación política como lo es la democracia, luego de vivir un proceso de homogenización ideológica y autoritarismo, como fueron las dictaduras (Anchorena, 2016; Olaza, 2017).

Por otra parte, Broquetas (2016) proporciona una lectura distinta del concepto de restauración en el campo del análisis político social. Esta autora denomina "reacción" a las transformaciones sociales provocadas por movimientos sociales, y "restauración" a procesos conservadores que buscan mantener un determinado orden social y un imaginario en la población que favorece el statu quo. A diferencia de la mayoría de la literatura revisada para este trabajo, el planteamiento de 
Broquetas (2016) muestra que la noción de restauración puede entenderse como conservación de un sistema político; sin embargo, la discusión presentada en este artículo se distancia de esta interpretación y, en su lugar, coincide con la mayoría de autores revisados que presentan la restauración como un procedimiento favorable a la regeneración celular, la recuperación de ambientes naturales o de objetos valiosos para la identidad y la cultura de una comunidad.

En cuanto a lo jurídico, el desarrollo más importante del concepto de restauración ha sido en la justicia restaurativa. Uno de sus objetivos es la reconstrucción de un contexto relacional que permita a todos los participantes de un conflicto convivir en una comunidad, de ahí que no solo se atiende a las necesidades de las víctimas, sino también se pretende reparar la dignidad de los agresores, quienes según Villa, Tejada, Sánchez y Téllez (2007) se deshumanizan en el proceso de la violencia, y es necesario considerar los medios y estrategias para que esa dignidad sea restaurada. Esta participación de todos los involucrados en el conflicto es tal vez uno de los elementos que diferencia la restauración de otros procesos como la reparación, cuya preocupación se centra en "curar a la víctima para que se recupere, con independencia de si se corrigen las cosas relativas al delincuente o a la comunidad” (Dussich, 2012, p. 58).

Otro elemento que define a la justicia restaurativa es su énfasis no solo en el resultado sino también en el proceso. Esta concepción, según Van Camp (2014), busca facilitar la participación de las partes involucradas y una solución a los daños y consecuencias que satisfaga a todos; no solo se habla de la víctima y el agresor, sino también de las comunidades. Esta participación activa se supone satisfactoria para los participantes pues, como lo plantea Márquez (2005), son ellos mismos quienes están creando justicia, en vez de recibirla pasivamente desde un sistema institucional.

Algunas experiencias de procesos de justicia restaurativa son el caso de Creggan en Irlanda del Norte y los tribunales Gacaca en Ruanda. Herrera y Bello (2010) expresan que a pesar de la desmovilización del Ejército Republicano Irlandés (IRA), en Creggan los niveles de inseguridad y la desconfianza hacia las autoridades se mantuvieron, e incluso se incrementaron. Excombatientes y comunidad se vieron en la necesidad de buscar alternativas para solucionar esta situación y aplicaron el modelo de justicia restaurativa, el cual consistió en que un grupo de excombatientes voluntarios recibían las demandas de la comunidad, hacían entrevistas con las víctimas y los ofensores, y buscaban conjuntamente soluciones que fueran convenientes para promover un cambio de actitud en los agresores.

Los tribunales Gacaca son otro ejemplo de justicia restaurativa, creados para atender las consecuencias del genocidio en Ruanda. Rettig (2008) relata que los jueces, personas escogidas por la misma comunidad, no necesariamente abogados, y conocidos como inyangamugayo (quienes detestan la deshonestidad), fueron los encargados de los juicios comunitarios. Los jueces partían de una clasificación de los hechos, cuestionaban a los acusados por lo sucedido, 
verificaban la exactitud y profundidad de las confesiones, pedían a los acusados y a la comunidad agregar lo que consideraran necesario, hacían una deliberación y emitían el veredicto, teniendo en cuenta la participación de todos y cada uno de los involucrados. Es importante tener en cuenta que los jueces no actuaban como persecutores ni como defensores, su función era llegar a la verdad a través de la facilitación del diálogo comunitario. Este proceso, en palabras de Carter (2007), ha reorientado el curso de la justicia en Ruanda, dado que ha enfatizado en la confesión, el arrepentimiento y el perdón, y el principal objetivo ha sido la reconciliación, permitiendo por lo menos la primera entrada de los agresores a las comunidades.

Los ejemplos planteados evidencian el lugar de lo restaurativo en los procesos de reconciliación social, que según Bar-Tal y Bennink (2004) tiene que ver con cambios profundos en las motivaciones, concepciones, creencias, actitudes, objetivos, emociones y relaciones, no solo de los directamente involucrados, sino también de la sociedad en general respecto al conflicto.

Los abordajes del concepto de restauración, desde distintos campos de conocimiento analizados, han tenido como propósito comprender mejor la complejidad y riqueza del concepto. A continuación se ampliarán algunas ideas aplicadas a la noción de restauración psicosocial con sobrevivientes del conflicto armado en Colombia.

\section{La restauración psicosocial como reconocimiento de los sobrevivientes y del sufrimiento social vivido}

Según Butler (2006), el reconocimiento se refiere a la apreciación de las personas, grupos y comunidades que han sufrido daño, como seres valiosos, como se dijo anteriormente. Este reconocimiento les permite no solamente confirmar el valor de sus propias vidas sino también de las vidas de los otros; se enriquece no solamente la versión del sí mismo, sino las múltiples versiones de lo que los otros son o de lo que pueden ser como comunidad, en lo que se pueden convertir.

Incluir a todos los que han sufrido daño a causa del conflicto armado, como sobrevivientes, significa trascender las categorías dicotómicas, que hacen difícil reconocer no solamente las causas del daño y sus efectos, sino también las respuestas que todos los afectados han llevado a cabo para hacer frente a las diversas situaciones de adversidad que han vivido. Esto es común a las experiencias de restauración ecológica participativa y de justicia restaurativa, como ya se enunció anteriormente.

Si bien el esclarecimiento de la verdad de los hechos ocurridos durante el conflicto armado y la aplicación de la justicia para castigar a los responsables es un proceso social y político de máxima relevancia en Colombia, se considera que, en términos de restauración psicosocial, es necesario trascender estos enunciados y hacer énfasis en las capacidades, la agencia y los recursos que 
permiten a los sobrevivientes hacer frente a situaciones devastadoras, identificando claramente su capacidad de acción intencional (Cobb, 1997).

En la literatura revisada se encontró alusión especialmente a la necesaria transformación de la categoría de víctima a las de sobrevivientes, agentes o testigos. Desde el punto de vista de la restauración psicosocial, se considera que lo que se plantea sobre las víctimas es aplicable también a los victimarios, pues todos ellos, como sobrevivientes, sufrieron los efectos del conflicto, lo han enfrentado con sus propios recursos y requieren vivir procesos de restauración en relación al significado del daño. Por ejemplo, López y Londoño (2007) consideran que la noción de víctima no necesariamente es útil para recuperarse de los efectos de la violencia. Así mismo, la Comisión Nacional de Reparación y Reconciliación (2009) se refiere a un tránsito de víctima a testigo, ya que esta última denominación expresa sujetos sociales que se dan cuenta de su historia y de la responsabilidad que tienen con su recuperación. Esto se relaciona también con lo expresado por Denborough (2008), quien considera que en ningún caso de trauma o privación las personas son solo recipientes de sufrimiento, sino personas que responden a través de sus habilidades y conocimientos. Molina (2010), por su parte, propone transformar la condición de víctima hacia la de actor social, que "toma decisiones cada vez que puede" (Molina, 2010, p.65) y participa en un amplio y complejo sistema de relaciones.

Otros autores como Arias, Arévalo y Ruiz (2002); Estrada, Ibarra y Sarmiento (2003); MartínBeristain (2004, 2012); Arévalo (2010); Estrada, Ripoll y Rodríguez (2010); Rebolledo y Rondón (2010); Wilches (2010); Duque y Gordon (2012); Moreno (2013); y Moreno y Moncayo (2015), coinciden en la necesidad de transformar la categoría de víctima en otra más generativa, que reconozca las múltiples acciones desplegadas para hacer frente a su difícil situación, desconectarlas con posibles cargas valorativas asociadas a los efectos negativos de la violencia, al déficit, al trauma y al riesgo.

De otro lado, el reconocimiento también se refiere al sufrimiento que viven los sobrevivientes como consecuencia del conflicto armado. Como ya se enunció anteriormente, si bien el sufrimiento de los sobrevivientes es subjetivo, su causa no está puesta en la interioridad del sujeto, sino que se ha desplegado en un contexto, es un hecho social y como tal se reconoce. Villa (2013) expresa que "la acción centrada en el sujeto individual conduce a una inspección de la propia vida que quizás no es el centro ni de la demanda ni del daño” (p. 67). Esto quiere decir que, aunque las afectaciones son diversas y atienden a la subjetividad, provienen de situaciones colectivas.

Martín-Baró (1984) plantea que el sufrimiento de los sobrevivientes es la respuesta más normal posible antes los acontecimientos anormales que les ha tocado vivir. Centrarse en los síntomas implica una concentración en el déficit, lo que es contrario a los propósitos de lo restaurativo, entre los cuales está, según Márquez (2005), facilitar la búsqueda de soluciones 
creativas y la despatologización del sufrimiento. Las causas estructurales del sufrimiento no son intrapsíquicas sino que resultan de la exposición a los acontecimientos violentos en los contextos situados en los que los sobrevivientes han vivido. En la restauración psicosocial, entonces, los sobrevivientes, las comunidades, el Estado, las instituciones, se hacen cargo de las rupturas y daños que se han presentado, para poder superar las culpabilizaciones individuales que no favorecen la restauración, la integración a un contexto seguro, ni la reconciliación.

Hacer énfasis en los efectos patológicos individuales de los hechos violentos, es decir individualizar y psicologizar las reacciones de las personas al conflicto armado, ha sido objeto de crítica entre varios autores (Lykes, 2001; Hamber, 2004; Clancy y Hamber, 2008; MartínBeristain, 2008) pues tiene un efecto de despolitización y negación de los derechos políticos a la verdad, la justicia y la reparación, oculta las causas de la violencia, dificulta el logro de la justicia social y genera un nuevo estigma a los sobrevivientes: el de enfermos mentales.

Según Das (como se citó en Ortega, 2008) es necesario preguntarse por formas de acción e intervención que realmente contribuyan a la recuperación de la dignidad, el empoderamiento y la recuperación, y sugiere favorecer procesos de escucha y reconocimiento. Entender la restauración psicosocial como reconocimiento de los sobrevivientes y del sufrimiento social vivido, tiene implicaciones en la manera como se desarrolla el proceso restaurativo. Moreno y Díaz (2016) plantean que la manera como se perciben y se enuncian a las personas que han sufrido un hecho violento, tiene repercusiones en la forma como los facilitadores de procesos restaurativos se relacionan con ellos, el tipo de actividades que se proponen y la forma como se desenvuelven las mismas. Esto también es apoyado por autores como Sánchez y Musitu (1996), Martín-Beristain (2004) y Meertens (2006).

Por tanto, de acuerdo con Lugo (2017), para llevar a cabo un proceso de restauración psicosocial es fundamental el reconocimiento de las personas que han sufrido daño como interlocutores válidos y respetables, con capacidad para hacer uso de la palabra y ser parte de la audiencia que también escucha. Cuando se está frente a interlocutores válidos se da crédito a su narración, se respeta su posicionamiento; se contextualiza el conocimiento experto expresado en diagnósticos e historias clínicas; se pregunta de forma interesada para entender mejor, para aprender de las experiencias de los sobrevivientes; se escucha realmente. La interpretación de lo que ha sucedido en las vidas de los sobrevivientes se lleva a cabo de forma conjunta y no desde la posición autoritaria del experto.

\section{La restauración psicosocial como acción conjunta y dialógica}

La restauración psicosocial se desarrolla y repercute en las relaciones humanas, es decir, las relaciones son el medio y el fin, dado que es a través de ellas que se despliegan los procesos de vinculación que permiten el diálogo conjunto, con lo cual se busca reconstruir el tejido 
relacional y de interacciones que permita a los involucrados en el conflicto co-existir de manera segura. Siguiendo a Lederach (1998), es en las relaciones humanas donde se despliegan los conflictos y, allí mismo, donde radicará la solución. De acuerdo a lo anterior, la restauración implica un proceso colectivo, pues como lo indica Villa (2013) no se reduce a si las acciones son grupales o individuales sino a un marco ontológico que reconozca e integre el contexto, la historia, los derechos, el sujeto, los otros. Si el conflicto se da en el seno de un contexto relacional, es en ese mismo contexto donde se dirigen los esfuerzos y las acciones desde un punto de vista restaurativo; es decir, se propone propiciar la interacción, el establecimiento de vínculos, de relaciones de confianza como una condición necesaria para acciones subsiguientes.

El mecanismo de esa acción enmarcada en lo colectivo es el diálogo. Su importancia, según Van Camp (2014), radica en que las personas no solo quieren expresarse y ser escuchadas, sino que también buscan una interacción, es decir, una comunicación que transforme a los participantes. Según el autor, a través de la interacción que permite el diálogo, los sobrevivientes pueden verificar haber sido comprendidos por sus antagónicos, constatan el nivel de afectación que su historia tiene para los demás, transforman la idea inicial que han tenido sobre los otros, y en algún sentido contextualizan sus comportamientos.

Para Herzig y Chasin (2001), colaboradores del Public Conversation Project, el diálogo es entendido como una conversación motivada por una búsqueda de entendimiento más que por acuerdos concretos o soluciones, que ofrece a quienes participan la oportunidad de escuchar y ser escuchados, de modo que quienes hablan puedan ser oídos; hablar y dejar que les hablen de manera respetuosa; desarrollar y profundizar el entendimiento mutuo; conocer la perspectiva de los otros y reflexionar sobre los propios puntos de vista. De acuerdo con Van der Bos, Vermunt y Wilke (1996), la asociación entre la voz y la justicia es consistente y confiable, es decir que tener voz aumenta la percepción subjetiva de justicia y la escucha favorece el reconocimiento.

La restauración como acción conjunta, también se relaciona con que se requiere la participación activa de todos los involucrados. Como Van Camp (2014) plantea, lo restaurativo se desarrolla desde la convicción de que los afectados por el conflicto son los protagonistas del proceso. Esto coincide con lo presentado sobre restauración ecológica participativa, y el tribunal participativo de Gacaca. La restauración psicosocial maximiza el control del proceso por parte de sus participantes, lo que muchas veces se ha perdido durante el conflicto. Entonces, es necesario que la participación sea voluntaria, que llegue hasta donde los participantes decidan y que determinen la pertinencia y oportunidad de cada una de las acciones, haciendo que estas se adapten a la subjetividad y no de forma contraria.

Lo anterior implica que el proceso se enmarque en una dinámica de flexibilidad, pues atiende no a las decisiones del facilitador, sino a la conducción de los propios participantes; aunado a ello el proceso no sigue lógicas lineales pues, como afirma Martín-Beristain (2005), las respuestas 
a un conflicto varían de persona a otra, de cultura a otra; de manera que no hay acciones estandarizadas, sino más bien un esfuerzo por generar escenarios creativos que trasciendan las lecturas tradicionales de otro tipo de procesos de atención, intervención o acompañamiento.

\section{La restauración psicosocial como una práctica simbólica situada}

Se entiende la restauración psicosocial como una práctica, al igual que la restauración de bienes culturales. Como afirma Butler (2002), una práctica reiterativa y referencial mediante la cual el discurso produce los efectos que nombra. Esto significa que la restauración no se da únicamente por la voluntad individual de quienes han padecido el daño o de quienes trabajan sobre ello, sino que se sitúa en discursos institucionales, disciplinares o culturales más amplios. De acuerdo con Lugo (2017), la restauración no es una práctica aislada, ingenua y aséptica de los discursos que la han creado y tiene el potencial de producir los efectos que el discurso mismo nombra. Estos discursos se constituyen en el marco donde la restauración, como proceso y práctica social artesanal de la vida diaria, toma forma.

Los escenarios para desarrollar la restauración psicosocial constituyen simultáneamente oportunidades para la expresión y la escucha. Se expresan el dolor, la rabia, la incertidumbre, el miedo, los pensamientos, el perdón, entre otras innumerables manifestaciones, que toman múltiples formas; es decir, no solamente pueden ser verbales, sino también escritas, visuales, artísticas, lúdicas; lo anterior por la fuerte relación que existe entre lo simbólico y la restauración. En últimas, de acuerdo con Lugo (2017), lo que se restaura es el significado que se ha construido sobre el daño, es decir, ¿a quién se atribuye?, ¿qué representa?, ¿cuáles son las consecuencias que ha tenido para la propia vida y las de los otros?, ¿cuáles son las implicaciones en la identidad y en la dignidad? ¿Qué recursos se tienen o se pueden obtener para salir adelante? ¿Cómo se puede expresar y comunicar este sufrimiento subjetivo?

Según la misma autora, la restauración del significado del daño enfrenta dificultades relacionadas con la memoria y el olvido. A pesar de la inmensa necesidad de olvidar los hechos violentos para protegerse del daño causado, es un esfuerzo infructuoso porque los recuerdos del daño permanecen y se expresan en pesadillas, sueños, palabras, gestos, dibujos o pensamientos negativos. Lo paradójico es que igualmente difícil es narrar lo que ha sucedido porque los recuerdos están partidos en piezas rotas y dispersas, y no se encuentra la voz que pueda darles coherencia y continuidad. Es tan difícil olvidar como recordar (Lugo, 2017). En la restauración psicosocial es fundamental que personas, grupos y comunidades puedan construir esa voz para narrar lo sucedido ante audiencias que puedan otorgar legitimidad social al daño y al sufrimiento causado. El hecho mismo de narrar lo sucedido, de relatar el impacto sobre las vidas, las costumbres y los ambientes trae consigo una anticipación del duelo, es decir, el acto mismo de narrar transforma el significado del daño y al realizarse siempre con otros (reales o imaginarios), para otros, no solo transforma al narrador sino también a su audiencia. 
Zehr y Toews (2004) exponen que lo simbólico contribuye a los procesos de restauración, dado que muchas veces las comunicaciones directas se dificultan, por ejemplo, en el acto de pedir perdón; de otro lado, manifiestan que puede considerarse más sincero un acto simbólico, que tiene connotaciones emocionales. En cuanto a los rituales, los mismos autores refieren que sirven como instrumentos de restauración cuando se institucionalizan nuevos comportamientos inclusivos que involucran a participantes de diferentes comunidades.

La restauración como práctica simbólica situada también tiene que ver con que toda restauración psicosocial tendrá que adaptarse a la vida cotidiana de los participantes, en términos de espacio, tiempo, intereses, estilos, generación, género, cultura, entre otros. De gran utilidad resultan recursos como las rutinas, los rituales, el juego, las metáforas, las historias, las celebraciones, el cuerpo (Lugo, 2017). Esto coincide con lo propuesto por Das (como se citó en Ortega, 2008) cuando afirma que es necesario:
(...) "descender a la cotidianidad", a "las rutinas y ritos cotidianos, a los gestos y murmullos del día a día, a los modos en los que la gente se viste, cocina, cuidan unos de otros, se asean, desean, se reprochan y castigan”. (p. 57)

Dentro de las consideraciones de lo simbólico puede encontrarse el arte, que también cumple un papel importante en los procesos restaurativos. Aunque el arte por sí solo no genera cambios, sí logra influenciar discursos, subjetividades, imaginarios, representaciones y formas de interrelación social, a través de la visibilización de situaciones, la imaginación de nuevas formas de relacionamiento y posibles horizontes de futuro deseables. En este sentido, el arte además de sensibilizar puede ser una herramienta para transformar la realidad.

En la revisión de antecedentes se han reconocido experiencias de grupos y organizaciones de víctimas que han tomado lo simbólico como medio para resignificar su realidad, hacer memoria y llamar la atención de la sociedad sobre su situación, como el caso de la Ruta Pacífica de las Mujeres $^{3}$ o las Madres de Soacha ${ }^{4}$. Como plantean Moreno y Díaz (2016), la construcción de memoria colectiva ha sido empleada en procesos de acompañamiento psicosocial, entre ellos los referidos por Molina (2006), Riaño (2006), Comisión Nacional de Reparación y Reconciliación (2009), Nieto (2010), Organización de los Estados Americanos (2011), Duque y Gordon (2012), Duque y Pineda (2013), Vidales (2013) y Villa (2014), los cuales se han desarrollado con el propósito de fortalecer la identidad cultural y reconstruir la historia de los hechos de violencia vividos.

\footnotetext{
${ }^{3}$ Organización de mujeres que apareció en el contexto político en el año 1995, y surgió con el propósito de hacer resistencia civil de la guerra y evidenciar el impacto de la misma en sus vidas.

${ }^{4}$ Organización conformada por las madres de jóvenes desaparecidos y asesinados en Soacha (Cundinamarca) por parte de miembros del Ejército de Colombia con el fin de dar "pruebas" de su eficiencia en la lucha contra la guerrilla. Caso conocido como "falsos positivos".
} 
La restauración con sobrevivientes del conflicto armado en Colombia: una propuesta de acción psicosocial

\section{Conclusiones}

La reflexión sobre la restauración necesariamente ha implicado la indagación de la categoría en diversas disciplinas. Esto ha permitido comprender algunas características del concepto y establecer puentes que terminan por esbozar la manera en la que se entiende la restauración en el plano psicosocial. Desde un ámbito biológico, la restauración es el proceso de recuperar la funcionalidad del organismo a través de una intervención intencionada de terceros, que además requiere de la participación activa de diferentes involucrados; mientras tanto, en un plano histórico y cultural se restaura aquello que tiene valor y sentido para las comunidades. Ahora bien, una importante referencia en el plano jurídico es la justicia restaurativa centrada en la participación de todos los involucrados en un delito, no como transgresión de la ley sino como hecho social que tiene repercusiones principalmente en un campo relacional, el mismo que debe ser restaurado.

Lo anterior permite comprender las nociones de la restauración como un acto colectivo, como acción conjunta, que involucra a todos los actores. Tiene como propósito establecer un diálogo que permita crear soluciones innovadoras a un conflicto, promoviendo una co-existencia segura entre las personas involucradas; lo anterior deja ver la diferencia entre la restauración y la sobrevivencia. Esta última categoría se refiere a prácticas cotidianas y espontáneas a través de las cuales las personas, grupos y comunidades logran tramitar el sufrimiento, mientras que la restauración alude a un proceso que responde a un propósito, y en el cual se involucran no solo los sobrevivientes, sino también las comunidades y personas no afectadas directamente por el conflicto, como los profesionales e instituciones que acompañan.

Ahora bien, en el contexto del post-acuerdo en el conflicto armado colombiano, la restauración se propone como acción psicosocial, donde es necesario considerar las particularidades de la población, reconocer los múltiples contextos sociales, políticos, culturales a los cuales pertenecen y acompañar respetuosamente. Lo psicosocial se entiende entonces como una relación dialéctica que existe entre lo personal y lo social, en la que los "traumas" se producen socialmente y se alimentan de la relación individuo-sociedad; las características y las consecuencias de los acontecimientos solo pueden entenderse en su contexto.

Desde la perspectiva psicosocial de la restauración, esta también implica el reconocimiento de los sobrevivientes como personas que tienen voz, una voz que merece ser expresada y escuchada, no solo por los efectos que tal experiencia narrativa tiene para ellos, sino también para las comunidades. La restauración psicosocial apela a lo simbólico que, además de facilitar la expresión, contribuye en la conservación de la memoria de aquello que quiere ser recordado. 


\section{Referencias}

Alanís, E., Jiménez, J., Pando, M., Aguirre, Ó. A., Treviño, E. J. y García, P. C. (2010). Efecto de la restauración ecológica post-incendio en la diversidad arbórea del Parque Ecológico Chipinque, México. Madera y Bosques, 16 (4), 39-54.

Alcántara, R. (2006). Un análisis crítico de la teoría de la restauración de Cesare Brandi. México, D.F., México: Instituto Nacional de Antropología e Historia (INHA).

Anchorena, Ó. (2016). Sociedad civil democrática en acción en la restauración: el republicanismo en Madrid. Espacio, Tiempo y Forma, SerieV Historia Contemporánea, 28, 73 94.

Arévalo, L. (2010). Atención y reparación psicosocial en contextos de violencia sociopolítica: una mirada reflexiva. Revistas de estudios sociales, 36, 29-39.

Arias, J., Arévalo, L. y Ruiz, S. (2002). Educación y conflicto armado. En M. Bello. y S. Ruiz. (Eds.), Conflicto armado, niñez y juventud: una perspectiva psicosocial (pp.179-277). Bogotá, Colombia: Universidad Nacional de Colombia.

Asociación Restauradores Sin Fronteras. (2012). Restauradores Sin Fronteras: el patrimonio como motor de desarrollo sostenible. Intervención, Revista Internacional de Conservación, Restauración y Museología, 3 (5), 45-49.

Bar-Tal, D. \& Bennink, G. (2004). The nature of reconciliation as an outcome and as a process. From Conflict Resolution to Reconciliation. New York: Oxford University Press.

Broquetas, M. (2016). Entre la reacción y la restauración. Derechas y violencia en Uruguay en los inicios de la crisis de la década de 1960. Estudios Ibero-Americanos, 42 (1), 142-166.

Butler, J. (2002). Cuerpos que importan: sobre los límites materiales y discursivos del "sexo". Buenos Aires, Argentina: Paidós.

Butler, J. (2006). Vida precaria: el poder del duelo y la violencia. Buenos Aires, Argentina: Paidós.

Butler, J. (2010). Marcos de guerra: las vidas lloradas. Madrid, España: Paidós.

Camacho, S. E. (2016). La restauración ecológica participativa: una visión juvenil desde el territorio de Ciudad Bolívar. Revista Electrónica Educare, 20 (2), 1-11. Recuperado de http://www.revistas.una.ac.cr/index.php/EDUCARE/article/view/7905

Carter, L. (2007). Justice and Reconciliation on Trial: Gacaca proceedings in Rwanda. New English Journal of International and Comparative Law, 14, 41-55.

Clancy, M. A. \& Hamber, B. (2008). Trauma, Peacebuilding and Development: An overview of key position and critical question. Paper present at the Trauma, Peacebuilding and Development Conference, Project run by INCORE and funded by the IDRCE, Nueva Delhi, India. 
La restauración con sobrevivientes del conflicto armado en Colombia: una propuesta de acción psicosocial

Cobb, S. (1997). Dolor y paradoja: la fuerza centrífuga de las narraciones de mujeres víctimas en un refugio para mujeres golpeadas. En M. Packman. (Ed.), Construcciones de la experiencia humana,Vol. II (pp. 17-62). Barcelona, España: Ed. Gedisa.

Comisión Nacional de Reparación y Reconciliación. (2009). Memorias en tiempo de guerra. Repertorio de iniciativas. Bogotá, Colombia: Punto Aparte Editores.

Denborough, D. (2008). Collective narrative practice: responding to individuals, groups, and communities who have experienced trauma. Adelaide, Australia: Dulwich Centre Publications.

Duque, N. y Gordon, D. (2012). Acompañamiento comunitario a poblaciones víctimas del conflicto armado: una propuesta de memoria histórica a partir de la fotografía. Cali, Colombia: Editorial Bonaventuriana.

Duque, N. y Pineda, J. (2013). El conflicto armado en el Pacífico colombiano. El caso

Sabaletas 2013. En A. Castillejo. y F. Reyes. (Eds.), Memoria, violencia y sociedad: debates y agendas en la Colombia actual (pp. 541-555). Bogotá, Colombia: Ediciones Usta Universidad Santo Tomás.

Dussich, J. (2012). Asistencia, recuperación y restauración de las víctimas. Eguszkilore, 26, 53-62.

Estrada, Á. M., Ibarra, C. y Sarmiento, E. (2003). Regulación y control de la subjetividad y la vida en el contexto del conflicto armado colombiano. Revista de Estudios Sociales, 15, 133-149.

Estrada, Á. M., Ripoll, K. y Rodríguez, D. (2010). Intervención psicosocial con fines de reparación con víctimas y sus familias afectadas por el conflicto armado interno en Colombia: equipos psicosociales en contextos jurídicos. Revista de Estudios Sociales, 36, 103-112.

Gergen, K. (1994). Realities and relationships: soundings in social construction. Cambridge: Harvard University Press.

González, O. L. (2017). Del olvido a la memoria: rescate de un mural de Luis Caballero en la Universidad de los Andes. Bogotá, Colombia: Ediciones UniAndes.

Gressler, S. y De Araújo, I. (2013). Ambientes restauradores: definição, histórico, abordagens e pesquisas. Estudos de Psicologia (Natal), 18 (3), 487-495.

Hamber, B. (2004). The Impact of Trauma: a psychosocial approach. Recuperado de http: / / www. brandonhamber.com/publications/pap-trauma1.htm

Herrera,W. y Bello, G. T. (2010). El proceso de paz en Irlanda del Norte: un modelo de justicia transicional desde abajo. En C. de Gamboa. (Ed.), El tránsito hacia la paz: de las herramientas nacionales a las locales (pp. 98-142). Bogotá, Colombia: Universidad del Rosario. 
Herzig, M. y Chasin, L. (2001). Promoviendo el diálogo a pesar de las diferencias. Guía de componentes básicos del Proyecto de Conversaciones Públicas (PCP). Boston: JAMS Foundation.

Kleinman, A., Das, V. y Lock, M. (Eds.). (1997). Social suffering. Berkeley, CA: University of California Press.

Lederach, J. P. (1998). Construyendo la paz. Reconciliación sostenible en sociedades divididas. Bilbao, España: Gernica Goguratuz.

López, O. L. y Londoño, L. M. (2007). Desplazamiento forzado en el oriente Antioqueño: estrategias familiares de sobrevivencia. Medellín, Colombia: Fondo Editorial Comfenalco.

Lugo, V. (2017). Disarmed warriors: narratives with youth ex-combatants in Colombia. Recuperado de https://shar.es/1TjI6W

Lykes, M. B. (2001). Artes creativas y fotografía en investigación-acción-participativa en Guatemala. En P. Reason. y H. Bradbury. (Eds.), Handbook of action research (pp. 363-371). London: Sage.

Márquez, A. (2005). La víctima en el sistema de justicia restaurativa. Derechos y Valores, 7 (16), 91-110.

Martín-Beristain, C. (2004). Enfoques y metodologías de atención psicosocial en el contexto del conflicto sociopolítico colombiano. Bogotá, Colombia: Terre des Hommes-Italia.

Martín-Beristain, C. (2005). Reconciliación luego de conflictos violentos: un marco teórico.Verdad, justicia y reparación. Desafíos para la Democracia y la Convivencia Social. Recuperado de https: / /www. colectivodeabogados.org/RECONCILIACION-LUEGO-DE- CONFLICTOS

Martín-Beristain, C. (2008). Memoria colectiva y reconstrucción de sociedades fracturadas por la violencia. En Romero, M. (Ed.), Verdad, memoria y reconstrucción: estudios de caso y análisis comparado. Bogotá, Colombia: Centro Internacional de Justicia Transicional (ICTJ).

Martín-Beristain, C. (2012). Acompañar los procesos con las víctimas. Bogotá, Colombia: Programa Promoción de la Convivencia.

Martín-Baró, I. (1984). Guerra y salud mental. Estudios centroamericanos, 429, 503-514.

Martínez, J., Montero, M., Córdova, A. y Vázquez, A. (2014). Restauración psicológica y naturaleza urbana: algunas implicaciones para la salud mental. Salud Mental, 37 (3), 217 224.

Mazón, M., Sánchez, D., Díaz, F. y Gaviria, J. (2017). Metodología para el monitoreo participativo de la restauración ecológica con estudiantes de primaria en plantaciones de cacao de Mérida, Venezuela. Biota Colombiana, 17 (1), 16-25.

Mbembe, A. (2011). Necropolítica. Madrid, España: Melusina. 
La restauración con sobrevivientes del conflicto armado en Colombia: una propuesta de acción psicosocial

Meertens, D. (2006). Reflexiones éticas, metodológicas y conceptuales sobre la investigación en desplazamiento y género. En M. N. Bello. (Ed.), Investigación y desplazamiento forzado: reflexiones éticas y metodológicas (pp. 112-125). Bogotá, Colombia: Red Nacional sobre Desplazamiento Forzado en Colombia.

Molina, L. E. (2005). Arqueología y restauración de monumentos históricos. Boletín Antropológico, 23 (65), 349-375.

Molina, N. (2006). Psicología política, resistencia y democracia: la resistencia comunitaria y la transformación de conflictos. Buenos Aires, Argentina: Editorial Proa.

Molina, N. (2010). Reconstrucción de memoria en historias de vida: efectos políticos y terapéuticos. Revista de Estudios Sociales, 36, 64-75.

Moreno, M. A. (2013). Psicoanálisis e intervención social. Revista CS, 11, 115-142.

Moreno, M. A. y Díaz, M. E. (2016). Posturas en la atención psicosocial a víctimas del conflicto armado en Colombia. El Ágora, 16 (1), 198-213.

Moreno, M. A. y Moncayo, J. (2015). Abordaje psicosocial: consideraciones conceptuales y alternativas de análisis en el escenario de atención a víctimas del conflicto armado. En E. Moncayo. y Á. Díaz. (Eds.), Psicología social crítica e intervención psicosocial: reflexiones desde la investigación (pp. 37-56). Cali, Colombia: Editorial Bonaventuriana.

Nieto, P. (2010). Relatos autobiográficos de víctimas del conflicto armado: una propuesta metodológica. Revista de Estudios Sociales, 36, 76-85.

Olaza, M. (2017). Afrodescendencia y restauración democrática en Uruguay. ¿Una nueva visión de ciudadanía? Revista de Ciencias Sociales, 30 (40), 63-82.

Organización de los Estados Americanos - Misión de apoyo al proceso de paz Colombia. (2011). Identidad e imágenes: Sabaletas, un pueblo con memoria. Cali, Colombia: Equilibrio Gráfico Editorial.

Ortega, F. A. (Ed.). (2008). Veena Das: Sujetos del dolor, agentes de dignidad. Bogotá, Colombia: Pontifica Universidad Javeriana, Universidad Nacional de Colombia.

Pizarro, V., Carrillo, V. y García, A. (2014). Revisión y estado del arte de la restauración ecológica de arrecifes coralinos. Biota Colombiana, 15, 132-149.

Rebolledo, O. y Rondón, L. (2010). Reflexiones y aproximaciones al trabajo psicosocial con víctimas individuales y colectivas en el marco del proceso de reparación. Revista de Estudios Sociales, 36, 40-50.

Recondo, R. (2006). Restauración e Identidad, salvando la memoria. Revista de Arquitectura e Ingeniería, O (0). Recuperado de http: / / www.redalyc.org/pdf/1939/193915923004. pdf 
Rettig, M. (2008). Gacaca: Truth, justice and reconciliation in postconflict Rwanda? African Studies Review, 51 (3), 25-50.

Riaño, P. (2006). El desplazamiento interno y los trabajos de la memoria. En M. N. Bello. (Ed.), Investigación y desplazamiento forzado: reflexiones éticas y metodológicas (pp. 99-111). Bogotá, Colombia: Red Nacional sobre Desplazamiento Forzado en Colombia.

Sánchez, A. y Musitu, G. (1996). Cuestiones éticas en la intervención psicosocial. En G. Sánchez. y M. Ochoa. (Eds.), Intervención comunitaria: aspectos científicos, técnicos y valorativos (pp. 79-85). Barcelona, España: EUB.

Squassina, A. (2016). El horizonte temporal en el proyecto de restauración. Loggia, Arquitectura y Restauración, 29, 8-27.

Van Camp, T. (2014). Victims of violence and restorative practices. Finding a voice. New York: Routledge.

Van der Bos, K., Vermunt, R. y Wilke, H. (1996). The consistency rule and the voice effect:The influence of expectations on procedural fairness judgements and performance. European Journal of Social Psychology, 26, 411-428.

Vera, H., Maragoto, C., Alonso, M., Sarduy, I., Rodríguez, N. y Denis, M. (2007). Programa de restauración neurológica en pacientes con trastorno de la migración neuroblástica. Revista Neurología, Neurocirugía y Psiquiatría, 40 (3), 65-73.

Vidales, R. (2013). Memory, narrative and the social transformation of reality. En S. Sacipa. y M. Montero. (Eds.), Psychosocial Approaches to peace-building. (pp. 89-110). Bogotá, Colombia: Springer.

Villa, J. D., Tejada, C., Sánchez, N. y Téllez, A. M. (2007). Nombrar lo innombrable: Reconciliación desde la perspectiva de las víctimas. Bogotá, Colombia: CINEP.

Villa, J. D. (2013). Horizontalidad, expresión y saberes compartidos: enfoque psicosocial en procesos de acompañamiento a víctimas de violencia política en Colombia. El Ágora USB, 13 (1), 289-327.

Villa, J. D. (2014). Memoria, historias de vida y papel de la escucha en la transformación subjetiva de víctimas / sobrevivientes del conflicto armado colombiano. El Ágora USB, 14 (1), 37-60.

Wilches, I. (2010). Lo que hemos aprendido sobre la atención a mujeres víctimas de violencia sexual en el conflicto armado colombiano. Revista de Estudios Sociales, 36, 86-94.

Zehr, H. \& Toews, B. (Eds.) (2004). Critical Issues in Restorative Justice. NY: Criminal Justice Press.

Zendri, L. (2011). Dimensión económica del patrimonio cultural: necesidad de adecuadas políticas en materia preservacionista. Anales, 41 (8), 404-415. 